\title{
SIR ARNOLD STOTT
}

Arnold Stott, who died on June 15, 1958 at the age of 72, was consulting physician and cardiologist to the Westminster and Royal Chest Hospitals. He qualified at St. Bartholomew's Hospital in 1909 and after holding the usual resident appointments became first a demonstrator in pathology and then chief assistant in the Children's department. He took his M.R.C.P. in 1912 and it was about this time that he came under the influence of Sir Thomas Lewis. Lewis recognized his ability at once and was keen to keep him as a whole-time assistant but Stott realised that his metier was not research but teaching and general medicine. His whole professional career, however, was profoundly influenced by his stay with Lewis and cardiology always remained his particular interest.

He served in France throughout the first world war and for the greater part of it was a pathologist in one the large general hospitals near Boulogne. On his return he became first a physician to the Ministry of Pensions and subsequently joined the staff of the Royal Chest and Westminster Hospitals. In his Ministry of Pensions work, he was recognized as a cardiac expert and played a prominent part in the swing away from the conception of organic mitral regurgitation as one of the most common

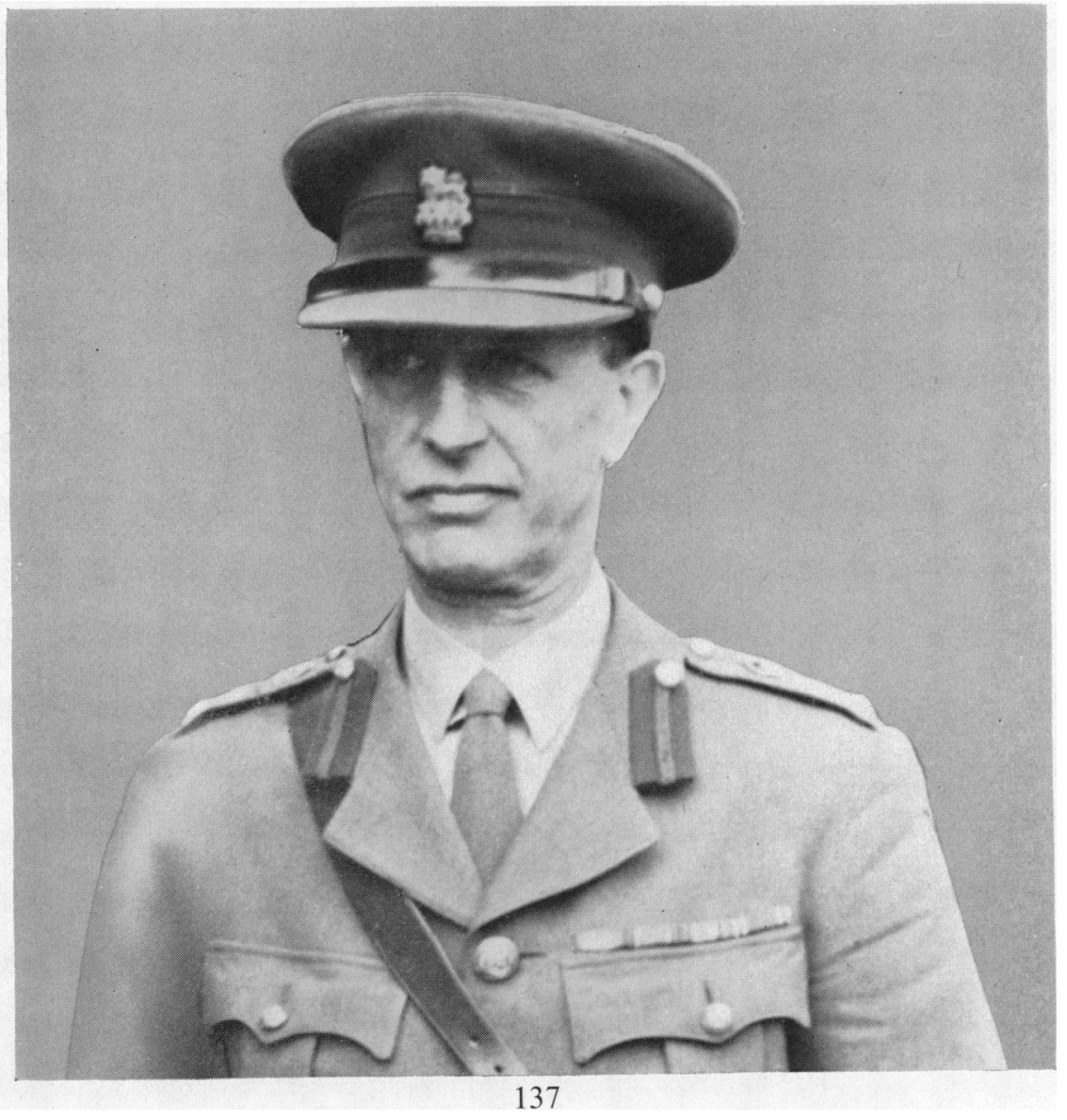


cardiac lesions. The Royal Chest Hospital was a clinical gold mine for him because, under a curious bye-law, patients with pulmonary tuberculosis were not admitted, and more than half the outpatients had cardiovascular disease. Even in those early days he foresaw the possibilities of cardiac surgery and although the hospital finances were always critical, he succeeded almost unaided in getting a modern surgical unit established. It was a severe blow to him when this old hospital which he had invigorated was completely destroyed by bombing in September, 1940 .

In Westminster he was the great teacher and his students found him a hard but just taskmaster. He understood the faults of inexperience and ignorance and there was always a twinkle in his eye when he corrected them, but his caustic criticism of negligence and laziness was devastating and salutary. His out-patient notes, written clearly and concisely in his own hand, were an example to his colleagues as well as to his students. In his later Westminster days much administration fell on his shoulders during the rebuilding of the hospital and its subsequent transfer to the Ministry of Health. His quick logical outlook and his foresight solved many of the difficulties of the turbulent committee meetings of this time; and it was the same clear judgment that was so invaluable in the committee of Consultants at the War Office and rightly earned him his K.B.E.

He could have had an enormous private practice and could have played a greater part in the affairs of the College. Some thought he was lazy, but in fact he felt morally bound to maintain the family tradition in a family business - a tradition that as he saw it meant treating the employees more and more as partners. Throughout the disastrous pre-war years of the cotton industry, he regularly visited Manchester-not for financial gain which was trivial, but to maintain a standard in humanity and workmanship. Although almost unknown there, his influence through his associates must still be effective.

Where a patient or a principle was concerned, Arnold knew only one truth and from this no power on earth could make him deviate. To those who did not know him closely, this gave an impression of austerity but he loved good companions, good food, and good wine, and was the moving spirit in many medical dining clubs. He was a keen gardener and fisherman and as President of the Flyfishers' Club was the ideal host.

He became a member of the Cardiac Club in 1927 and opened a discussion on Heart Disease of Unknown Aetiology in 1935. He was Chairman of the British Cardiac Society when it met in London in 1950 and held a most successful meeting at Westminster Hospital. Few of the younger generation of cardiologists knew him well because his interests were so varied. He belonged to an era of great clinicians when the transition from empiricism to science was just beginning in cardiology and he was not the least of these.

PETER KERLEY 